\title{
Hanno Wijsman, Two petals of a "fleur". The "Copenhague Fleur des Histoires" and the production of illuminated manuscripts in Bruges around 1480
}

\section{Maria Colombo Timelli}

\section{(2) OpenEdition}

\section{Journals}

Édition électronique

URL : http://journals.openedition.org/studifrancesi/6208

DOI : $10.4000 /$ studifrancesi.6208

ISSN : 2427-5856

Éditeur

Rosenberg \& Sellier

\section{Édition imprimée}

Date de publication : 1 novembre 2010

Pagination : 532-533

ISSN : 0039-2944

\section{Référence électronique}

Maria Colombo Timelli, « Hanno Wijsman, Two petals of a "fleur". The "Copenhague Fleur des Histoires" and the production of illuminated manuscripts in Bruges around $7480 »$ " Studi Francesi [En ligne], 162 (LIV | III) | 2010, mis en ligne le 30 novembre 2015, consulté le 13 janvier 2021. URL : http://

journals.openedition.org/studifrancesi/6208; DOI : https://doi.org/10.4000/studifrancesi.6208

Ce document a été généré automatiquement le 13 janvier 2021.

\section{c)}

Studi Francesi è distribuita con Licenza Creative Commons Attribuzione - Non commerciale - Non opere derivate 4.0 Internazionale. 


\title{
Hanno Wijsman, Two petals of a "fleur". The "Copenhague Fleur des Histoires" and the production of illuminated manuscripts in Bruges around 1480
}

\author{
Maria Colombo Timelli
}

\section{RÉFÉRENCE}

HANNO WIJSMAN, Two petals of a "fleur". The "Copenhague Fleur des Histoires" and the production of illuminated manuscripts in Bruges around 1480, dans «Fund og Forskning i det Kongelige Biblioteks samlinger», 47, 2008, pp. 17-72.

Ce long article est organisé en deux volets. Une première partie est consacrée aux manuscrits Copenhague, KB, Acc 2008/74 et Thott $5682^{\circ}$, qui transmettent la première rédaction de la Fleur des histoires de Jean Mansel (ca. 1446-1451): malgré des différences remarquables dans la mise en page, l'iconographie, la décoration, la graphie, ils constituent le premier et le dernier volume d'une même série. Dans la seconde partie, H.W. compare ces manuscrits avec d'autres de même origine - la ville de Bruges dans la seconde moitié du XV siècle - et notamment avec les mss Paris, BnF, fr 296-299, copie somptueuse de la version complète de la Fleur, produite par les mêmes artistes. Sur la base des ressemblances avec d'autres manuscrits brugeois, en particulier les 15.4-5-6 du Musée Plantin-Moretus d'Anvers (Chroniques de Froissart), H.W. peut affirmer l'existence d'un groupe de miniaturistes et décorateurs travaillant en collaboration afin de produire dans des délais relativement courts des copies luxueuses d'œuvres parfois très longues, et de concurrencer par là les imprimés parfois tout aussi somptueux sortis des presses de Colard Mansion. 
2 Cette importante contribution de H.W., enrichie par de nombreuses reproductions, ne considère jamais les textes transmis par ces copies: reste donc à espérer que les critiques qui s'intéressent à Jean Mansel et à Jean Froissart sauront conjuguer ces informations éminemment artistiques avec les aspects philologique, littéraire et linguistique. 